\title{
ANÁLISE DE PROCESSOS EROSIVOS COMO SUBSÍDIO PARA APTIDÃO AGRÍCOLA: APLICAÇÃO NO MUNICÍPIO DE ALIANÇA, ZONA DA MATA PERNAMBUCANA
}

\author{
Joaquim Pedro de Santana Xavier ${ }^{(a)}$, John Kennedy Ribeiro de Santana ${ }^{(b)}$, Fabrizio de Luiz Rosito \\ Listo $^{(\mathrm{c})}$ \\ (a) Graduando em Geografia, Departamento de Ciências Geográficas, UFPE, joaquimpedro05@gmail.com \\ (b) Graduando em Geografia, Departamento de Ciências Geográficas, UFPE, santanajohn87@ gmail.com

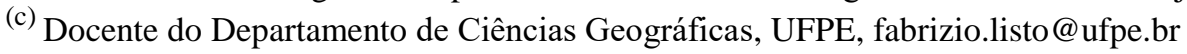

\section{Eixo: GEOTECNOLOGIAS E MODELAGEM ESPACIAL EM GEOGRAFIA FÍSICA}

\begin{abstract}
Resumo:
A Zona da Mata Pernambucana é uma área tradicional de cultivos agrícolas desde o período colonial. Entretanto, com o declínio do ciclo do açúcar, grandes áreas de cultivo foram substituídas por áreas mais degradadas, potencializando processos erosivos. Dessa forma, este trabalho possui como objetivo relacionar o mapeamento de áreas suscetíveis a processos erosivos lineares no município de Aliança-PE, elaborado a partir de uma análise multicritério em ambiente SIG, com o mapa de aptidão agrícola da área. Os resultados demostraram em sua maioria uma elevada concordância entre áreas fortemente suscetíveis a erosão e com menores aptidões agrícolas, confirmando a eficiência de ambos os mapeamentos.
\end{abstract}

Palavras chave: Processos Erosivos; Aptidão Agrícola; Análise Multicritério, Geotecnologias, Zona da Mata Pernambucana.

\section{Introdução}

O uso inadequado do solo possui grande potencial de causar desequilíbrios ambientais, tais como a potencialização de processos erosivos lineares, que podem causar desde a perda de solo agricultável até de vidas humanas, influenciando sobremaneira na aptidão agrícola dos terrenos (CHRISTOFOLETTI, 1980; GUERRA, 1994; CANIL, 2001; LEPSCH, 2002; XAVIER et al., 2010). Dessa forma, o uso de geotecnologias possui importante contribuição para o levantamento e manuseio de dados para posteriores estudos e intervenções, que estejam relacionados à dinâmica de processos superficiais da paisagem.

Somente no Estado de Pernambuco foram oficialmente registradas, entre 1991 e 2012, 32 ocorrências de erosão, sobretudo lineares (ravinas e voçorocas) e costeiras na Região Metropolitana do Recife, na Zona da Mata e no Agreste Pernambucano, muitas vezes influenciadas pela ocupação acelerada, comprometendo, por exemplo, a qualidade de áreas agrícolas (CEPED, 2013). Nesse contexto, destaca-se a Zona da Mata Pernambucana, tradicional área de cultivos agrícolas, principalmente pela plantação de cana-de-açúcar desde o período colonial. Inserido nesta região, o município de Aliança, mantém esta 
tradição econômica, porém com o declínio do ciclo do açúcar, as monoculturas de cana foram reduzidas, sobretudo em função da falência de engenhos e de usinas sucroalcooleiras da área. Dessa forma, grandes áreas de cultivo da cana foram substituídas por pastos, por vegetação rasteira de gramíneas e por áreas com solo exposto, degradadas e mais suscetíveis a processos erosivos, em função da potencialização do escoamento superficial. Sendo assim, este trabalho tem como objetivo avaliar a relação entre o mapa de suscetibilidade a processos erosivos lineares, elaborado a partir de uma análise multicritério, com o mapa de aptidão agrícola do município desenvolvido por Sousa et al (2008).

\section{2. Área de estudo}

O município de Aliança (Zona da Mata Pernambucana Setentrional) dista $72 \mathrm{~km}$ da capital Recife, e possui um território de $272 \mathrm{~km}^{2}$. A região se encontra em uma área de transição entre os tabuleiros costeiros sedimentares a leste e o Planalto da Borborema a oeste, apresentando em seu relevo, morros bastante dissecados pela drenagem (CPRM, 2005). A maior parte do município localiza-se nos níveis cristalinos antecedentes a Borborema, com altitudes variando de $10 \mathrm{~m}$ a 350m (BRASIL, 2000).

Sobre as superfícies suaves e onduladas localizam-se solos do tipo Planossolos e Argissolos, altamente suscetíveis a processos erosivos, nas mais elevadas, solos Litólicos e nos fundos de vales, Gleissolos (RESENDE et al., 1995; CPRM, 2005). A região tem uma rede de drenagem bastante desenvolvida, localizando-se dentro da bacia do rio Goiana. A litologia é composta pelos Complexos Vertente e Salgadinho, Granitóides indiscriminados e o Grupo Barreiras, esta última, uma cobertura sedimentar de idade miocênica a pleistocênica inferior, com grande fragilidade erosiva (CPRM, 2005). Possui um clima tropical quente e úmido com pluviometria média anual de 1.200mm (BRASIL, 1973), o que acarretou em uma vegetação original de Mata Seca, subcaducifólia (VASCONCELOS, 1949). Entretanto, esta vegetação original foi substituída por plantations de cana-de-açúcar, ainda no período colonial.

\section{Materiais e métodos}

Conforme os objetivos do trabalho, foram comparados os mapas de suscetibilidade a erosão e o mapa de aptidão agrícola do município (SOUSA et al., 2008), ambos em escala 1:25.000. O mapa de suscetibilidade a erosão foi elaborado a partir de uma análise multicritério pela combinação dos principais fatores condicionantes erosivos (uso da terra, declividade, curvatura, solos e litologia) por meio de mapas temáticos em ambiente SIG, no qual foram atribuídos diferentes pesos a cada um. Para a elaboração dos mapas topográficos de declividade e de curvatura foi elaborado, inicialmente, um Modelo Digital do Terreno (MDT) a partir da digitalização de seis cartas topográficas em escala 1:25.000 fornecidas pelo Exército Brasileiro. Tendo como base a vetorização dos dados planialtimétricos das referidas cartas, o 
MDT foi elaborado com resolução de $1 \mathrm{~m}^{2}$ por meio do módulo Topo to Raster (ferramenta 3D Analyst) no software ArcGIS 10.3. Com o MDT finalizado, foram elaborados os mapas de declividade e de curvatura por meio da ferramenta Raster Surface (ferramenta 3D Analyst) também no software ArcGIS 10.3. As cartas de litologia e de solos foram geradas, respectivamente, a partir da compilação de dados fornecidos pela CPRM (2005) e BRASIL (2000). Por fim, a carta de uso da terra foi elaborada a partir da fotointerpretação de imagens de satélite obtidas nos softwares Google Earth e BING em escala 1:20.000, cuja legenda foi baseada em Almeida e Freitas (1996) e Valladares et al (2012). Posteriormente, utilizaram-se as ferramentas Map Algebra, Raster Calculator (módulo Spatial Analyst/ArcGIS) para se calcular a suscetibilidade de acordo com os parâmetros supracitados. Para o cálculo foram utilizados pesos consagrados na literatura geomorfológica, de acordo com a importância de cada fator condicionante na deflagração de processos erosivos lineares: declividade 20\%, litologia $15 \%$, solos $25 \%$, uso da terra $20 \%$ e curvatura $20 \%$.

Para o mapa de aptidão agrícola, Souza et al. (2008) utilizaram-se dos critérios preconizados por Ramalho Filho e Beek (1994), tendo como base o levantamento de solos, deficiência de fertilidade, deficiência de água, excesso de água ou deficiência de oxigênio, suscetibilidade à erosão e impedimento à mecanização. Por meio de uma análise combinatória, os autores chegaram a diferentes classes de aptidão agrícola.

\section{Resultados e Discussões}

O mapa de suscetibilidade a erosão (Figura 1) apresentou aproximadamente $53 \%$ de classes de suscetibilidade a erosão forte, seguidos de $44 \%$ com índice médio, $3 \%$ muito forte e menos de $1 \%$ fraco. Destaca-se que a classe de suscetibilidade muito fraca não apresentou nenhum percentual na área. A classe forte é predominante muito provavelmente em função da presença elevada das classes de solos Argissolos Vermelho e Vermelho-Amarelo, Neossolos e Gleissolos, além de usos da terra com cana-de-açúcar, pastos e vegetação herbácea, todos muito suscetíveis aos processos erosivos. Destaca-se também a presença de encostas mais declivosas (superiores a 30\%) e côncavas, bastante suscetíveis aos processos erosivos, sobretudo pela concentração de fluxos de água em eventos de intensa pluviometria e com litologias de Granitóides indiscriminados.

Já o mapa de aptidão agrícola (Figura 2) apresenta predominantemente (cerca de 37\%), terras classificadas com aptidão restrita para lavouras de ciclo curto ou longo para diversos tipos de manejo (SOUSA et al., 2008), indicando que houve uma elevada concordância entre áreas suscetíveis a erosão e áreas impróprias para o cultivo agrícola. Por exemplo, em uma comparação mais detalhada entre os dois mapeamentos, observa-se que uma elevada área de aptidão agrícola restrita (maioria do município) coincide com classes de erosão fortes, influenciada pela fragilidade dos tipos de solos presentes na região. As terras de aptidão 
regular (cerca de 9\%), localizadas a sudeste de Aliança, também coincidem em sua maioria com classes de suscetibilidade à erosão forte.

Pontualmente, destacam-se as classes de boa aptidão para lavouras de ciclo curto ou longo (cerca de 16\%), das quais, as melhores áreas agricultáveis da região também se localizam, em sua maioria, com áreas de forte suscetibilidade erosiva, o que demanda um elevado cuidado técnico para as práticas agrícolas. À leste do município, por exemplo, observa-se uma gande área classificada como de suscetibilidade forte à erosão, mapeada com boa aptidão para lavouras de ciclo curto ou longo com possível manejo de médio a alto nível tecnológico.

À noroeste verificam-se feições classificadas como de média suscetibilidade, que coincidem com áreas de boa aptidão agrícola, regular ou restrita para silvicultura e/ou pastagem natural, muito provavelmente em função de litologias compostas em sua maioria por Granitóides indiscriminados, além de elevadas altitudes e declividades, devido à encostas que compõem a escarpa oriental do Planalto da Borborema. Nas áreas à sudoeste observam-se classes de média suscetibilidade a erosão, que se localizam em áreas com boa aptidão agrícola, regular ou restrita para a pastagem plantada, possivelmente por ser uma área coberta de Planossolos, cuja morfologia é mais resistente a erosão, apesar do relevo muito dissecado. Por fim, a sudeste, ocorrem áreas de média suscetibilidade a erosão com aptidão boa, regular ou restrita para a pastagem plantada, localizadas em áreas de várzea e com mata ciliares preservadas.

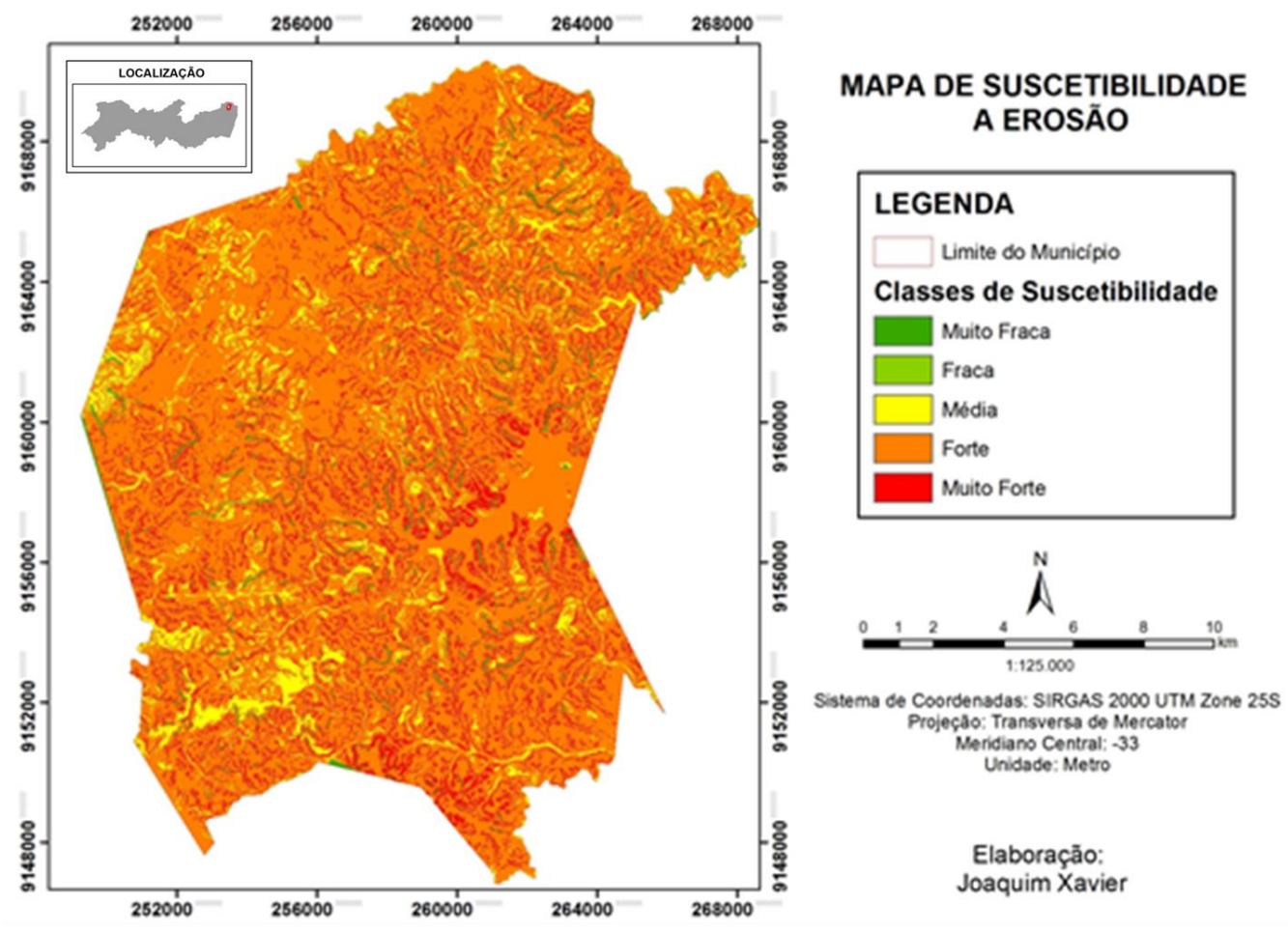

Figura 1 - Mapa de suscetibilidade a erosão do município de Aliança- PE 

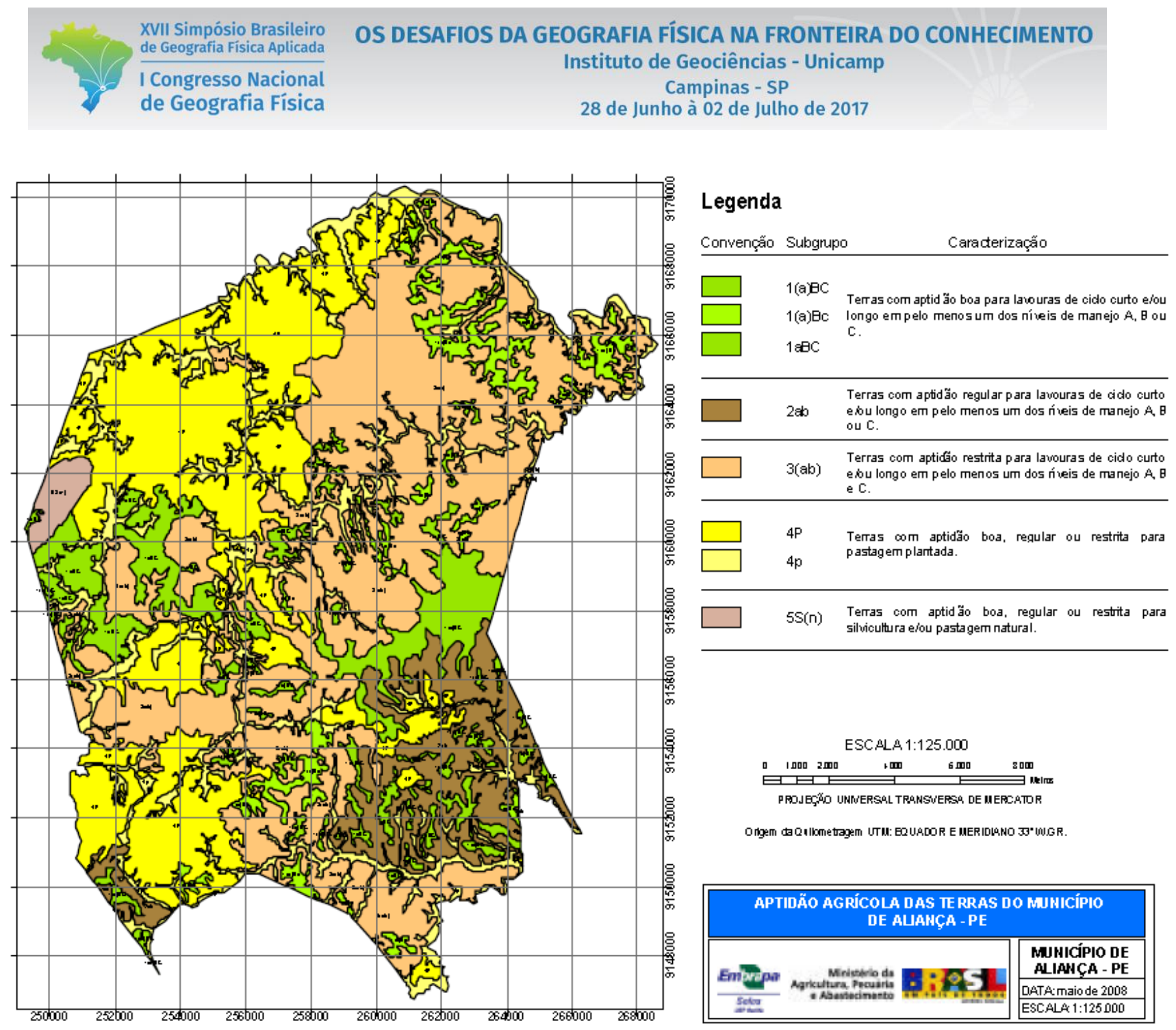

Figura 2 - Mapa de aptidão agrícola do município de Aliança- PE. Fonte: SOUSA et al., 2008.

\section{Considerações Finais}

Avaliando-se os dois mapeamentos, foi possível observar uma elevada concordância entre classes suscetíveis à erosão e com baixa aptidão agrícola, confirmando a eficiência do mapa de suscetibilidade erosiva a partir da análise multicritério. Especificamente para o município de Aliança, observou-se que nas áreas em que predominam cultivos agrícolas, ocorreram às classes mais suscetíveis à erosão. Tal situação necessita de um cuidado técnico pela gestão pública, tendo em vista a relevância destes produtos agrícolas para a economia do município e que possuem grande potencialidade de serem afetados por processos erosivos. Dessa forma, os produtos cartográficos, bem como as análises geradas podem ser utilizados pela gestão pública no melhor planejamento do território ao integrarem ferramentas administrativas, tais como Planos Diretores e as Leis Orgânicas do município. 


\section{Bibliografia}

ALMEIDA, M.C.J.; FREITAS, C.G.L. Uso do solo urbano: suas relações com o meio físico e problemas decorrentes. In: Anais do $2^{\circ}$ Simpósio Brasileiro de Cartografia Geotécnica, p. 195-200, São Carlos, 1996.

BRASIL. Ministério da Agricultura, Pecuária e do Abastecimento. Levantamento de Reconhecimento de Baixa e Média Intensidade dos Solos do Estado de Pernambuco. V. 1. Recife: EMBRAPA, 38p. (Boletim Técnico, 11). 2000 .

BRASIL. Ministério da Agricultura. Levantamento exploratório-reconhecimento de solos do Estado de Pernambuco. V. 1. Recife: Sudene, 359p. (Boletim Técnico, 26), 1973.

CANIL, K. Metodologia para Elaboração da Carta de Risco de Erosão do Município de Franca, SP. In: VII Simpósio Nacional de Controle De Erosão. Goiânia. Anais.... p. 1 - 8, 2001.

CENTRO UNIVERSITÁRIO DE ESTUDOS E PESQUISAS SOBRE DESASTRES (CEPED). Atlas Brasileiro de Desastres Naturais: 1991 a 2012. Universidade Federal de Santa Catarina. 2 ed. Volume Pernambuco. Florianópolis: CEPED - UFSC, 130p, 2013.

CHRISTOFOLETTI, A. Geomorfologia. São Paulo: Edgard Blucher, 1980.

CPRM (Recife). Ministério de Minas e Energia. Projeto Cadastro de Fontes de Abastecimento por Água Subterrânea Estado de Pernambuco: Diagnóstico do município de aliança. Recife: p. 1-20, 2005.

GUERRA, A. J. T. Processos Erosivos nas Encostas. In: GUERRA, A. J. T.; CUNHA, S.B. (Orgs.). Geomorfologia: uma atualização de bases e conceitos. Rio de Janeiro (RJ): Bertrand Brasil, p. 149-209, 1994.

LEPSCH, I. F. Formação e Conservação dos Solos. São Paulo (SP): Oficina de Textos, 178p, 2002.

RAMALHO FILHO, A.; BEEK, K. J. Sistema de avaliação da aptidão agrícola das terras. 3a. ed. rev. Rio de Janeiro: Embrapa - CNPS, 1994.

RESENDE, M.; CURI, N.; REZENDE, S. B. de; CORREAA, G. F. Pedologia: base para distinção de ambientes. Viçosa: NEPUT, 1995.

SOUSA, A. R.; SILVA, A.; SANTOS, M.; FILHO, J.; ACCIOLY, L.; FERRAZ, L. Aptidão Agrícola das Terras do Município de Aliança, Pernambuco. Manejo e Conservação do Solo e da água no Contexto das Mudanças Ambientais, Rio de Janeiro, ago. 2008.

VALLADARES, G. S.; GOMES, A. S.; TORRESAN, F.E.; RODRIGUES, C. A. G.; GREGO, C, R. Modelo Multicritério Aditivo na Geração de Mapas de Suscetibilidade à Erosão em Área Rural. Pesquisa Agropecuária Brasileira, Brasília, v. 47, n. 9, p. 1376-1383, set, 2012. 


\begin{tabular}{|c|c|}
\hline $\begin{array}{l}\text { XVII Simpósio Brasileiro } \\
\text { de Geografia Fisica Aplicada } \\
\end{array}$ & $\begin{array}{l}\text { OS DESAFIOS DA GEOGRAFIA FÍSICA NA FRONTEIRA DO CONHECIMENTO } \\
\text { Instituto de Geociências - Unicamp }\end{array}$ \\
\hline $\begin{array}{l}\text { I Congresso Nacional } \\
\text { de Geografia Física }\end{array}$ & $\begin{array}{l}\text { Campinas - SP } \\
28 \text { de Junho à } 02 \text { de Julho de } 2017\end{array}$ \\
\hline
\end{tabular}

VASCONCELOS, S. As Regiões naturais de Pernambuco, o meio ambiente e civilização. Rio de Janeiro: Freitas Bastos, 1949.

XAVIER, F.V.; CUNHA, K.L.; SILVEIRA, A.; SALOMÃO, F.X.T. Análise da suscetibilidade à erosão laminar da Bacia do Rio Manso, Chapada dos Guimarães, MT, utilizando Sistemas de Informações Geográficas. Revista Brasileira de Geomorfologia, v.11, p.51-60, 2010. 